Gyarmathy E, Senior, J. (2016) The inclusion of multiple exceptional gifted students in talent development programmes. Interaction synthesis of both provision form and content. Gifted Education International July 11, doi: 10.1177/0261429416656500

\title{
The Inclusion of Multiple Exceptional Gifted Students in Talent Development Programmes
}

\author{
Interaction synthesis of both provision form and content
}

\author{
Éva Gyarmathy \\ Institute of Cognitive Neuroscience and Psychology of the Hungarian Academy of Sciences \\ gyarmathy.eva@gmail.com
}

John Senior

Education Consultant

john.senior@hotmail.com

\begin{abstract}
Models of giftedness in the 21st century tend to describe talent as a social construct. Research now indicates that certain talented populations that are composed of multiple exceptional individuals are excluded from talent development programmes. Recognising how well the environment best fits individual needs at particular key development moments, shifts the emphases of focus regarding gifted education significantly. The provision for and the development of multiple exceptional gifted individuals from this perspective can engender far greater possibilities than previously imagined earlier.

In Hungary we started to create innovative networks for the encouragement and development of effective, inclusive provision. The networks have however replicated many of the problems of the former provision for talented individuals and groups. The further development of content and appropriate forms of programmes, need to be synchronised through networks of innovative provision and evaluation. The proposed complex provision is suggested as a solution for the new forms of talent development that are open to the multiple exceptional gifted population regardless of the populations' needs being understood and perceived by different audiences as being variously extreme, diverse and novel.
\end{abstract}

A system utilising key aspects of Bloom's taxonomy, Renzulli's Enrichment Triad and Gardner's Multiple Intelligences is proposed.

Keywords: inclusion, multiple exceptional gifted, talent-point network, complex provision 


\section{Talent and normality}

Two characteristics that inform the criterion of normality as applied to an individual are that the characteristics can be seen as being both typical and desirable. When these two coincide, there is no problem, but when the desirable is not typical, or the typical is not desirable, difficulties may arise.

This view can be explored and considered by considering the following example:

No one is considered as disabled for not having wings. Wings are not typical, even though they might be desirable. Should someone, however, grow wings instead of strong legs they will count as abnormal, because legs are desirable and typical, while wings, although desirable, are not typical. In addition, there are few who could teach a person born with wings how to fly. The situation would change, if these desirable wings were to become typical. In that case, those who cannot fly would be abnormal.

Talent can be experienced and recognised as a natural force, a specific attitude and a specific mode of reaction. As such, it necessarily differs from what is regular and expected, but it cannot be called abnormal, when the talent is seen as being a desirable divergence. The concept of normality is; it could be argued indifferent as regards considering talent.

Elements of talent can be regarded as desirable, but not necessarily as being typical characteristics, when they are regarded as unusual or disturbing. Their desirability is also highly dependent on society and the culture they exhibit themselves. Moreover, above a certain level of tolerability, high intelligence, creativity and internal drive are regarded as abnormal irrespective of the environment.

Talent is therefore regarded as normal only as long as its manifestation meets the criterion of desirability. Talent coupled with extreme, unconventional elements (such as wings) will lead to difficulties, because it is neither typical, and even if it were desirable, it would be difficult to integrate into the society which is not adapted or able to accept and integrate the unconventional.

Sliwka (2010) describes three approaches with regard to the process of changing the perception, acceptance and understanding of social, ethnic, gender and ability differences:

1. Homogeneity - Segregation: difference not seen, those who differ are abnormal and should get segregated provision.

2. Heterogeneity - Integration: difference seen as challenge to be dealt with, and effort is needed to integrate.

3. Diversity - Inclusion: difference seen as asset and opportunity, and the provision is a flexible network that can include all the deviances.

This approach can be extended to the gifted persons, and normality considered as merely a theoretical matter where inclusion is flexible, embracing and ultimately accepted.

Social inclusion in the psychological sense is a stable dynamic equilibrium emerging from the interaction of the individual and its environment. The equilibrium is determined by the interaction of the individual and its environment. The outstandingly gifted and, in general, so called atypical talents which are difficult to reconcile with the talent-image of the dominant, prevailing specific culture and society, disrupt this equilibrium and inclusion is less successful. In other words; the gifted or multiple exceptional talents are identified as hardly acceptable deviance from what is considered tolerable and desirable.

We would like to strongly emphasis that a person with normal integration can still be a gifted/multi exceptional gifted person. 
The greater the difference between the talent and its environment, the greater the difficulty its acceptance as a natural element of the society. It is evident that in an environment that can accept, and even support heterogeneity, the integration problems of talented individuals are smaller than against a rigid background that curbs idiosyncratic ways and solutions even using subtle administrative tools.

Fewer problems arise when society considers diversity to be an asset, and inclusion is the normal approach. It follows that the prevalence of manifest talent is therefore connected to the flexibility of the environment.

Populations in which the proportion of manifest talents is low are compelled to develop, barely develop or even develop abnormally, when an environment not suitable for their characteristics exists. The evidence of unbalanced indicators of the multiple exceptional gifted population in the talent population is one sign of system rigidity.

\section{Talent predisposition}

A gifted individual can perceive an achievement as a potential for new activities. This attitude leads to more activities, and thus improved practice and further developments. This makes the attainment of new achievements possible.

The task of provision and of education in general, is to keep the individual active, and ensure an appropriate environment for their activities. Our key problem in regard to the talented/multi exceptional talented individual is what an "appropriate environment" is.

Development means changing. It is difficult to conceive of a single environment that is conducive to all forms of talent development, because an environment conducive to development should constantly change with the changes. In other words, as change occurs, so further change becomes inevitable and must in turn be addressed. It is even more evident in the case of talent, as the development of the gifted person is faster than is usually understood.

Gifted individuals differ from the majority in their behaviour and attitude, but this difference will only be manifest as talent if the environment reacts to it in a way that is appropriate for the individual's internal characteristics and internal drives. The external interventions into the activities, and the development of talent, should be adapted to the individual predisposition. This predisposition influences the opportunities available through at least three of its components:

(1) individual characteristics,

(2) the most appropriate environment for the development of the individual characteristics,

(3) the given environmental opportunities.

The dynamic interaction of these components results in development, irrespective of its direction. This is thus a phenomenon functioning independently of a definition of development and achievement with reference to human values. The way we can have an influence, however, is to 'ride the wave' or in other words, respond in a flexible, dynamic interactive manner, whereby we may be able to support, regulate and direct the process.

For the moment, however, education, special education and gifted education are all under the delusion that they themselves spawn these waves of propulsion. That it is indeed a delusion is shown by the waves spattering over our heads, in which children and adults alike are drowning. Several studies have shown the untenability of the previous approach to gifted education (Lipsey, Wilson, 1993, Freeman, 2006; Ziegler, Stoeger, Vialle, 2012). 
An increasing number of studies today indicate that, contrary to earlier hopes, we are just unable to fathom the factors influencing the development of a human individual to as great an extent as we have thought. New epigenetic knowledge has also led to a new molecular biological interpretation of the processes of human physical, mental and emotional development.

Epigenetics describes the dynamic mutual influence of the environment and genes, which is far more exciting and challenging to respond to the needs of a learner than we thought earlier. It has turned out that not everything is coded in genes that hereditary processes may change as a result of environmental effects. Environmental effects at certain critical points during ontogenic development can have a lifelong influence, and may even span generations. Thus, events, educational effects, nursing, traumas and physiological circumstances that occur during the life of parents and grandparents have an effect on the functioning of the genes coded in the DNA and are therefore hereditary effects.

Jean Lamarck described his theory on the inheritance of acquired characteristics in writing in 1809. The Lamarckian view was later, however, eclipsed by Darwin's theory of "natural selection". Epigenetics has then basically discovered the processes that signal the reconcilability of the two theories (Handel \& Ramagopalan, 2010).

According to the formal definition, an epigenetic event is: "the structural adaptation of chromosomal regions so as to register, signal or perpetuate altered activity states." (Bird, 2007, p. 398).

Thus, the "hardware", the genes are given, received from our parents without change through inheritance. The hardware can of course get damaged, but does not change fundamentally. What changes, is the software, which controls the functioning of the hardware. This message is constantly rewritten through generations by the environment, and the software rewritten by environmental effects on our ancestors and by ourselves, controls our "hardware", or in other words, our genes.

The science of physiology thus describes how the environment can dynamically affect our hereditary possibilities. Predisposition is thus not simply the interaction of the individual and its environment, but is a bio-psycho-sociological process potentially spanning multiple generations.

Understanding the above elements of predisposition can help us approach our work in education and development more humbly:

As previously alluded to:

(1) Individual characteristics constantly change as a function of both internal and external conditions. They are therefore themselves influenced by the predispositions enacted on individual genetic and epigenetic factors. Therefore,

- characteristics identified at one point cannot be interpreted without reference to earlier events and factors,

- characteristics identified at one point are not fully valid at some later point.

Since this change can be especially substantial with respect to talent development, assessments of giftedness produce even more incidental results than average assessments.

(2) The environment appropriate for the development of individual characteristics is not constant. The needs of the individual with respect to the environment will differ at each point of their development. Again, due to the faster development of talent, environmental factors needed for its development should be planned to be even more dynamic than usual, so as to avoid an inhibitory effect. The environment appropriate for development thus not only differs highly by individual, but 
the external conditions necessary at a certain period will change even for one individual.

(3) The possibilities of the environment can differ by subject area, but can also change themselves. Nature and also human culture, in particular, changes constantly. There are therefore no constantly given external factors, only varying possibilities, which can affect development.

In the predisposition-based approach to gifted education, the solution is the harmonic correlated motion of the changes and development of the individual and the environment. All of this is nothing new, as the system-based approach is more and more an inexorable part of the comprehensive gifted education that now addresses sociological, psychological, pedagogical, and even physiological issues. What is new is that this system has to be complimentary to a flexible network to be appropriate for the provision.

\section{The actiotope model}

According to Ziegler, Stoeger and Vialle (2012), the gifted education system corresponding to the mechanistic approach of the 20th century, is not efficient, and even constitutes a downright disadvantage for future performance.

Ziegler and colleagues worked out the system they called the "actiotope model" essentially within the predisposition-approach. Being built on the dynamic interaction between environment and individual, the focus is directed on the "action" rather than the "traits" (Ziegler, Vialle, Wimmer, 2013).

The "actiotope" is basically the total of the bio-psycho-sociological interaction activities between the individual and the environment. With respect to devising a gifted education system appropriate for as wide a range of individuals as possible, the most important element is the so called "sociotope", that is, environmental configuration, about which the authors also think in terms of actions rather than traits.

The challenge of having to adapt the environment to the constantly changing needs of the individual, rather than the individual to the environment, far exceeds our possibilities if we continue to think in terms of models and systems based on the earlier paradigm.

\section{Talent-point network}

Péter Csermely, a biochemist specializing in network science, transferred the principle of network groups such as cellular networks or internet connections, which function far more efficiently than the simple sum of its members, to the gifted education system. On his initiative, the Hungarian gifted education programme, designed to support talents, is based on a talent point network. The principle of organization follows a network-based approach: its design is not characterised by a single centre and uniform connections, but instead, the system is built on regional, professional and skill-based connections (Csermely, 2008).

The birth of such a gifted education network is an outstanding achievement. The network has been running for seven years now and includes over a thousand recognised talent-points in Hungary. The true distribution and number of secondary network points is difficult to estimate without further research. The 'network' has therefore become highly suitable for a scientific study of the new kind of gifted education environment. The study is urgent as a similar network is to be built on a European level ${ }^{1}$

1 http://talentcenterbudapest.eu/node/421 


\section{The effect of the mechanistic view of talent}

The provision for the gifted in Hungary is based on the mechanistic view of talent, and unfortunately the network adheres to the traditional uniform requirements under a centralized control. In other words, the design based on a new approach has to work with the old content. The question is whether the new design can change the old content or the content will affect the form.

The mechanistic, assessment-based approach to gifted education is built on the principle, primarily applied in areas of natural science that the scientific approach uniformly consists of three steps:

1. definition,

2. identification,

3. development.

This is what 20th century gifted education followed (Solano, 1979; Rosemarin, 1999). Children, however, are not like, for example, potatoes, in that, specimens intended for different uses should be sorted along the same criteria.

Irrespective of the nature of our intervention, the 20th century principle, which is intended as universal, cannot be used for supporting gifted people. Psychology and pedagogy is beginning to increasingly disengage from the old rigid confines and employ scientific approaches of its own. Talent support is now also going new ways, because earlier solutions have decidedly not lived up to the hopes put in them, as outlined above.

The mechanistic approach to gifted education mirrors the selective practice in education, which means exclusion, segregation and confines the accepted and supported ways of functioning, learning and development to a narrow lane of change. Thereby, it can only ensure an appropriate environment for a limited number of conforming talents.

\section{Multiple/twice exceptional gifted and its mirror in the provision}

It is clear from the studies that talented individuals who are disadvantaged for some reason are still under represented in talent programmes. They are the twice/multiply exceptional, who are characterised by some other form of exceptionality beside giftedness. This most commonly involves

- a socio-cultural situation,

- an ethnic-minority situation,

- neurological differences,

- behavioural and emotional differences,

- sensory-kinaesthetic differences.

In such cases, which can be regarded as discrete, minority situations, the needs of talented individuals concerning their environment will surface even less than regular, and there is even less chance for them to gain access to external factors appropriate for their needs. This is the essence of being disadvantaged. Whether gifted or not, for those whose predispositions differ significantly from that of the majority, access to appropriate provision is poorer in comparison to the majority (Gyarmathy, 2013).

"As above, so below." A gifted provision network mirrors the problems in gifted education itself. If gifted education entails exclusion, so will the gifted provision network.

The statistics about the Hungarian talent point network confirms that socio-culturally disadvantaged regions are under-represented in the talent point system. The number of the 
disadvantaged is especially low among the institutions that are "accredited" or " highly accredited", that is, among those that are approved to have met suitability requirements. In addition, gifted education groups which we can call exceptional (such as alternative schools, clubs, underground art groups), and who are less able to assert themselves, will also have more difficulty in gaining admission to the talent point system, and especially to the group of accredited institutions.

Gifted education works the least well in disadvantaged areas, even though precisely these areas are (would be) the source of exceptional groups of talents (Gyarmathy, 2010). For exactly this reason, those in control of gifted provision programmes are trying to fix holes using positive discrimination. There is a separate programme for disadvantaged individuals demonstrating exceptional talents. The core of the problem remains, however, despite having picked a few 'smiling faces' from the 'talent' population.

The problem is not inequality, inequality is natural. The problem lies in an incorrect selection method. The resources intended for gifted education are less accessible for those who do not fit properly into the official approach to giftedness, since their needs are different from regular.

The way the talent point network functions depends on the content we fill it with. Talent points basically mirror the situation of the talents themselves.

Table 1 The approach to gifted education is manifested in the gifted education system. Theorems that apply to both individuals and systems (based on Gyarmathy, 2013)

\begin{tabular}{|c|c|}
\hline Gifted individual & Provision of gifted \\
\hline $\begin{array}{c}\text { Unique solutions can lead to development in interaction with the } \\
\text { environment, and therefore the guarantee for development lies in } \\
\text { respecting individual needs. }\end{array}$ \\
\hline $\begin{array}{c}\text { Natural development is compromised proportionately to the increase in } \\
\text { the ratio of compulsory solutions. }\end{array}$ \\
$\begin{array}{c}\text { Assessment and selection on the basis of an early and narrow system of } \\
\text { criteria veers natural development off course and narrows down the } \\
\text { probability of meaningful and appropriate identification/support. }\end{array}$ \\
\hline The appearance of independence stems from trust. \\
\hline Narrow control leads to lack of independence or resistance. \\
\hline Performance-orientation strengthens competitiveness. \\
\hline Encouraging the diversity of solutions strengthens co-operations. \\
\hline $\begin{array}{c}\text { Administrative procedures support administrative patterns and elements } \\
\text { that do not fit this pattern gradually become hidden and/or disappear. }\end{array}$ \\
\hline
\end{tabular}

The approach to gifted education is manifested in the gifted education system, and vice versa. The problem of a new system of gifted education, the talent network shows is the greatest obstacle 
and source of danger preventing successful progress; forcing the mechanistic approach makes gifted education administrative, turn a network into a cage.

The tangles and rich fabric of the network ensure diversity, and the potential for rapid change and speedy reaction. The rigid fossilised nature of an over-controlled talent cage can obstruct the effective development and acceptance of meaningful gifted provision practice.

The mutual influence of diversity systems presents an excellent opportunity to interpret phenomena showing up in one system in the other one, as well.

\section{A working talent network}

The mirror effect of form and content can also be identified in the form of positive reinforcement. Parallel to the Hungarian talent point network, is another network developed in Hungary, This network initiative is influenced by a different approach to giftedness, advocated by the Council for the Support of the Gifted with Special Educational Needs.

Members of the network include institutions and organizations which themselves share this approach. The essence of the approach is that it is built on trust, with control and evaluation taking place in a natural way via natural selection, rather than on the basis of an artificial selection.

The participating institutions and organizations are fully independent; their work is not controlled directly by the network. That is, all institutions that enlist into the network are identified as capable, professional institutions. Differences are an advantage, so the network strives to avoid uniformity. The system is thereby able to cope with diverse tasks.

The activities relating to various tasks have automatically yielded a selection of talent points which are more active and more competent. These points engage in and receive more tasks. The network helps its members on the basis of client feedback to carry out their tasks as efficiently as possible. This is the only form of control.

Sharing information ensures not only that, clients have access to appropriate provision, but also that members of the network can take on tasks which are suited to them. The network supports development and self-improvement by disseminating available training opportunities, and even offers regular training opportunities of its own.

The network organizes a monthly workshop dedicated to a topic with the aim of getting to know a particular method. Participation in the workshop is voluntary and free of charge. This is basically the sole organized opportunity for personal meetings, although members of the network form smaller groups organized around particular tasks and meet more frequently.

The essence of dynamic cooperation in an efficient network is as follows:

1. The network connects members and networks which are efficient in themselves.

2. The members of the network are independent and the network does not influence its members through qualifications.

3. The members of the network are different, that is, they bring different solutions into the field of activities.

4. The network is characterised by a vigorous exchange of information.

5. Members of the network share tasks with other members which they are unable to solve alone.

6. The success of the members of the network is increased by being able to cope with most tasks within the network through diversity and wide area coverage. 
7. The activities of the members of the network are self-reinforcing, since tasks they engage in and cope with bring on new ones. Success therefore leads to more activity in a natural way.

The talent view of the network's institutions and organizations is appropriate for their functioning and also mirrors it. They focus on partnership and continuous fine tuning:

- They regard a great variety of abilities as values, and do not rank different ability- or skills areas.

- They pay attention to both strengths and weaknesses.

- They respect idiosyncratic ways of development.

- They expect activity, rather than achievement.

- They offer opportunities for diverse activities.

- They support group and individual activities alike.

An example for such an institution is a small school at Hejőkeresztúr, situated in a disadvantaged region, and $70 \%$ of whose students are diagnosed as multiple disadvantaged and having special education needs, which still achieves results equivalent to the national average on competence studies, and whose students regularly participate in international competitions (K. Nagy, 2013a,b).

\section{The talent network and the talented individual}

The interaction between network and the target of the network is evident. The mirror reflection between form and content can be discerned in this case, as well.

The major opportunities in a network:

a) transmission of information,

b) free choice of tasks and activities.

Also an effective gifted education organization offers opportunities for development through the

a) transmission of information,

b) free choice of tasks and activities.

Three indicators can measure the efficiency of the members of the network:

1. the tasks they engage in and complete (a task can be regarded as complete if the member either undertakes ongoing provision relating to a case, or successfully delegates it),

2. organizing methodological presentations (transfers own methods to others),

3. participating in methodological presentations (broadens its knowledge).

All three indicators measure concrete activities, and all three indicates concrete efficiency or its increase. The indicators for the development of talents in gifted provision are based on the very same principle, that is, assessment is another area where there is a mirror relation between the gifted education environment and the individual participating in gifted education.

Three indicators measuring the efficiency of an individual participating in gifted education:

1. activity in individual's area of expertise (learning, courses, field trips, studies, competitions, performances etc.),

2. mentor activity (transfers knowledge and experience in individual or group format),

3. participation in group activities (interest and participation in opportunities beyond the individual's own activity).

The levels measured by different indicators may differ significantly from individual to individual. The ratio of activity in the three areas can differ significantly for both different members of the network, and individuals in gifted provision. In extreme cases, even a single indicator may indicate 
an outstanding level, and this would represent at least as great efficiency as when, for example, all three indicators measure the same level.

\section{Complex development}

The network co-ordinator, the Council for the Support of Talents with SEN in Hungary does not seek to adapt clients to the methods at hand, but seeks to find the institution and professional capable of providing appropriate provision to the client. This is easy to do, since the network covers different educational institutions, clubs, associations, significant individuals, museums and even institutions providing health care from all over the country.

In a complex system, we do not talk of talent individuals, since they are still under development. Talent is the goal. Clients come to us with their needs, potentials and hindrances. Appropriate activities reveal what the client's specific needs are.

Educational development groups formed spontaneously on the basis of the needs of a client participate in the education of an individual or a small group. The goal is complex development building on the individual's strengths, irrespective of whether the client entered educational development because of their talent or their deficits.

Gifted education does not mean the direct development of talent, but instead, the paving of the road towards talent development. The clients have to go down the road themselves. The professionals only provide expertise and the opportunities to support and nourish independent learning.

According to the approach of complex development, everyone should be treated as a potential talent, though not everybody is considered gifted. Thus, gifted provision can be extended to everyone even without the use of the label "gifted".

\section{Appropriate provision for the gifted is the ultimate form of education and development}

Complex development can serve as the basis for even the most efficient form of education. The problems faced by minorities with specialities have always drawn attention to weak points that also constitute a problem to the majority. Provision for the gifted can therefore indicate the general problems of education, while special talents, such as multiply exceptional talents, can in turn indicate the weaknesses of gifted education.

In the system of complex development, provision can be organized through understanding the interests and activity of the client. Interest reveals the direction of development that the client is open to, and activity reveals the current level of the client's development.

- Interest is the best indicator of developmental possibilities, because a motivated individual is ready for a given activity and, releasing the desire and understanding of the benefits of persistent practice, leading to the development of abilities. Interest therefore has an immensely high predictive strength.

- Observing activity can help determine the level of abilities the individual possesses in a given area. This level is determined by predisposition, that is, it is the result of the interplay of the internal and external factors present for the individual beforehand. It therefore represents the current state of affairs, and has less predictive force than interest.

A development plan can be compiled on the basis of the characteristics observed in these two areas. Interest and activity delimit the area that Vygotsky (1978) called the "zone of proximal 
development". This is the zone in which an individual can develop most efficiently, because the challenge is optimal.

Finding the optimal task and activity is the key to efficient development and education, irrespective of the abilities and opportunities of the individual, because it can help maximize the effort on the part of the individual.

There are several models describing the system of thinking and development. These can provide a useful framework for development, and may even help us cut down the lengthy assessment procedures or become part of the development plan.

\section{Systemic understanding and development}

In the practice of complex understanding and development through activity, it is especially important to have a usable framework for secure orientation. The models of Bloom (1956) and Gardner (1983) are quite suitable to this end.

Gardner (1983), though writing about multiple intelligences, basically described the chief ability areas. These are the areas that must absolutely be part of the provision. Here we use them in the developmental order and not in the academic importance order that has been used by Gardner.

The system of Bloom (1956) is the series of cognitive levels going from simple to more complex. It helps us understand the interdependent domains of learning, and the corresponding structure of appropriate development and education.

The first two levels of Bloom are about experience:

1. Knowledge

2. Comprehension

Knowledge and comprehension are not, yet restricted by encyclopaedic knowledge. The characteristic activity at this level is free exploration. This is also the first level in the classical enrichment triad of Renzulli (1977). It is suitable for inciting interest, because there is no assessment at this point, yet, since its essence is exploration, trial and understanding through experience. The learner has more strength for exploration without the stress created by evaluation.

This kind of learning is most characteristic of young children up to the age of about eight. Every learning programme and education initiative should also start at this level, because we all enter new areas as "young children". Once a learner is past this, he or she will automatically start looking for the next level. At that point, the learner's activity goes beyond the first two levels.

The second two levels of Bloom make it possible for knowledge to become conscious. This entails a higher level of activity:

3. Application

4. Analysis

At these levels, we assess. There are good and bad solutions. Application of the rules and analysis of the material make it possible to be methodical, to process the material.

This is the characteristic level of school learning, in which practice plays a major role. At this level, thinking involves categories and relations. Sufficient practice and rule application can lead to a higher level of cognitive processing.

Renzulli's (1977) type II enrichment programme is based on such kind of developmental activities. Even gifted education cannot leave stages of development out of consideration; at most, progress 
will be faster. Deepening knowledge through practice and analysis is the way to methodical knowledge.

Those who gain sufficient practice in some area are able to move to a higher level of knowledge. In creative thinking, relations are dissociated from the object, and the individual is capable of abstraction. School education seldom brings the individual to this level, but of course it could be argued that may not even be the task of school education.

5. Synthesis

6. Evaluation

These cognitive levels belong to the realm of the training of the gifted. Naturally, the more school education will involve higher cognitive functioning, the more gifted provision will ensue.

These cognitive levels are characteristic of the mature thinking of the teenage and adult years. Creative functioning is dependent on being able to put information into new frameworks by breaking away from the concrete. Critical thinking, with which we can rearrange our knowledge along new criteria by appraising multiple approaches and possibilities, is the kind of thinking which makes outstanding intellectual achievements possible.

Renzulli's type III enrichment programme targets real tasks and creation, which means that at this point, thinking has reached the highest two levels.

If we fill all these levels with different areas of ability, we arrive at an activity matrix which is capable of both:

- mapping the types and areas of activity characteristic of the individual

- establishing developmental activities.

Any activity can be entered into the matrix, although most activities could fit into more than one slot. Note: The depth of the activity increases in the table going right and going down.

Table 2 The matrix of the framework for complex development

\begin{tabular}{|c|c|c|c|c|c|c|}
\hline \multirow{2}{*}{ activity } & \multicolumn{2}{|c|}{ Free exploration } & \multicolumn{2}{c|}{ Conscious learning } & \multicolumn{2}{c|}{ Critical thinking } \\
\hline area & Knowledge & Comprehension & Application & Analysis & Synthesis & Evaluation \\
\hline kinaesthetic & & & & & & \\
\hline musical & & & & & & \\
\hline spatial-visual & & & & & & \\
\hline linguistic & & & & & & \\
\hline logical & & & & & & \\
\hline interpersonal & & & & & & \\
\hline intrapersonal & & & & & & \\
\hline
\end{tabular}

Developmental activities should start off at the point where the client feels secure. Therefore, the activities offered to the clients should be as varied and multifarious as possible, so that the activity 
characteristic of the client can be determined in as great detail as possible. The above-mentioned Hejőkeresztúr Model, which works with highly heterogeneous groups and promotes gifted education along the above principles, has a very similar approach (K. Nagy, 2013a, b).

Table 3 An example for interest areas and cognitive levels

The thickness of the arrow shows the strength of the interest characteristic of a given client, while its length shows the cognitive level characteristic of the activity of the client in the given area.

\begin{tabular}{|c|c|c|c|c|c|c|}
\hline activity & \multicolumn{2}{|c|}{ Free exploration } & \multicolumn{2}{|c|}{ Conscious learning } & \multicolumn{2}{|c|}{ Critical thinking } \\
\hline area & Knowledge & Comprehension & Application & Analysis & Synthesis & Evaluation \\
\hline kinaesthetic & ᄃ & & & & & \\
\hline musical & & & & & & \\
\hline spatial-visual & & 2 & & & & \\
\hline linguistic & & $>$ & & & & \\
\hline logical & & $>$ & & & & \\
\hline interpersonal & & & $\sqrt{2}$ & & & \\
\hline intrapersonal & $\Longrightarrow$ & & & & & \\
\hline
\end{tabular}

The level of challenge characteristic of the environment will affect the level of activity. Thus, an achievement cannot be dissociated from the area and situation in which it occurred. In the above table, we recorded observation results with reference only to the area and cognitive challenge. In reality, however, a myriad of further small and not so small details will have an effect on the activity and its outcomes. Even a competent observation of an activity fails to reveal the road that actually led to the activity in question. The history of the client can reveal further important information.

There are many ways of carrying out development, but the most efficient way is to exploit strong interest as much as possible and target the cognitive level of the client in the relevant area. In a network comprising of a large variety of workshops and professionals, gifted education can be in a position to ensure and offer-a wide variety and level of activity.

\section{A conjoining of solutions}

Once we started compounding different methods in systemic development, blending new approaches, and working solutions, programmes and support for gifted individuals ceases to be an insurmountable task. On the contrary, as shown earlier, complex systems are effective if we combine consistent procedures skilfully.

The similar fundamentals of the predisposition-approach and the actiotope model, combined with the complex development connected to the network approach to gifted education can provide a 
new solution to efficient skills development systems. Practical solutions of learning/teaching and development can help fill the system with content.

Content and form, if matching, have a good chance of raising methodology to a higher level, and make it possible for gifted education to provide usable frameworks and methods for general developmental and educational work, as well.

Multi-level, interest-based gifted education is beneficial for everyone. This is best promoted by a cup-shaped system of gifted education:

- For the wide public in everyday provision

- For groups of interested individuals

- For outstanding individuals

- For talents

Extensive development during everyday activities makes it possible to raise client interest level. Those who wish for more activity in some area than their peers should be given the opportunity for further development. Some of these individuals will become outstanding in their field and manifest themselves in achievement, and from this pool of outstanding individuals, in turn, talents will emerge.

\section{Summary}

Inclusion does not mean ignoring individual differences and the exclusion of individual provision. On the contrary, inclusion greets the diversity in both the person and forms of provision. A talent network is inclusive and extremely effective if it provides a wide range of activities on different levels of educational provision meeting individual needs.

A complex system that takes consideration of the age of the population, individual levels of learning and cognitive development and the different areas of the human abilities is a useful base for the effective, economic and efficient promotion of inclusive education of the special learners even if they are gifted, having difficulties, or special requirements of any kind.

Inclusion doesn't mean a restriction of the provision within classrooms rather it assumes a different level of appropriate to the individual provision.

There are many new initiatives informing the provision for the gifted. A deliberate conjoining of these methods, adapted and applied to local needs, can be the most effective change in the development of talent provision.

\section{References}

Bird, A. (2007) Perceptions of epigenetics. Nature, Vol. 447. 24. doi:10.1038/nature05913

Bloom, B. S. (1956) Taxonomy of Educational Objectives: The Classification of Educational Goals. Longman Publishing Group, White Plains.

Csermely, P (2008) Creative elements: network-based predictions of active centres in proteins, cellular and social networks. Trends Biochem. Science. 33, 569-576.

Freeman, J. (2006) 'Giftedness in the Long Term'. Journal for the Education of the Gifted, 29, 384403.

Gardner, H. (1983) Frames of mind: The theory of multiple intelligences. Basic Books, New York. 
Gyarmathy, E (2010) Atipikus agy és a tehetség II. - Az átütő tehetség és a tehetségvizsgálatok ma. [Atypical brain and talent II. - Outstanding talent and talent assessments today] Pszichológia. 30, 1, 31-41.

Gyarmathy, E (2013) A tehetséggondozás változási kényszere. [The necessary change in gifted education.] Iskolakultúra, 3-4.

Handel, A. E., Ramagopalan, S. V. (2010) Is Lamarckian evolution relevant to medicine? BMC Medical Genetics 2010, 11:73 http://www.biomedcentral.com/1471-2350/11/73

K. Nagy, E (2013a) Acquiring status treatment techniques by creating a lesson plan. Pedacta, BBE, Romania, 1.

K. Nagy, E (2013b) How can we create an equitable classroom? In: J. T. Karlovitz (Ed) Questions and Perspectives in Education. International Research Institute. 109-115.

Lipsey, M.W., Wilson, D.B. (1993) The efficacy of psychological, educational, and behavioral treatment. American Psychologist, 48, 1181-1201.

Renzulli, J. (1977) The Enrichment Triad Model: A guide for developing defensible programs for the gifted and talented. Creative Learning Press Inc. Wethersfield.

Rosemarin, S. (1999) Giftedness as a function of right mediation. Gifted Education International Vol. 14, 4-11.

Sliwka, A. (2010) From homogeneity to diversity in German education. In OECD (Ed.), Educating Teachers for Diversity: Meeting the Challenge. OECD Publishing. pp. 205-217

Solano, C. H. (1979) The First D: Discovery of Talent, or Needles in a Haystack: Mathematically Gifted Child. In Colangelo, N. \& Zaffrann, R.T. (Eds): New Voices in Counselling the Gifted. Kendall \& Hunt, lowa. 93.

Vygotsky, L. S. (1978) Mind in society: The development of higher psychological processes. Cambridge, MA: Harvard University Press.

Ziegler, A. Stoeger, H. Vialle, W. (2012) Giftedness and Gifted Education: The Need for a Paradigm Change. Gifted Child Quarterly, October, 56. 194-197.

Ziegler, A. Vialle, W. Wimmer, B (2013) The actiotope model of giftedness. In S. N. Phillipson, H. Stoeger, \& A. Ziegler (Eds.) Exceptionality in East-Asia: Explorations in the actiotope model of giftedness. London: Routledge. 1-17. 